\title{
Inteligibilidade racional e historicidade ${ }^{1}$
}

\author{
MICHEL PATY
}

\section{Introdução. As ciências na história, um campo de problemas filosóficos}

A

S REFLEXÕES PRESENTES neste texto pertencem ao que poderíamos chamar de filosofia da história da ciência, na verdade, tanto à história da ciência quanto à filosofia da ciência. Estas reflexões incidirão sobre alguns aspectos bem circunscritos e somente retomarei as questões gerais tradicionalmente debatidas sobre as relações entre a filosofia da ciência e a história da ciência para declarar, desde já, que estas reflexões querem testemunhar à sua maneira que a história da ciência, como aliás também as ciências no seu estado atual, constituem para a filosofia da ciência um campo muito rico e vivo de problemas. Digo efetivamente um campo de problemas (filosóficos e epistemológicos) a inventariar e não um espaço de aplicação de teses a serem ilustradas, como seria o caso para uma filosofia da ciência normativa que fosse, na realidade, entendida como separada da história da ciência.

E estes problemas, pegos em flagrante, concretamente por assim dizer, estão aptos a renovar oportunamente um domínio onde, freqüentemente, houve a tendência, ao longo do século já encerrado, de enredar-se em debates algo escolásticos, sem dúvida porque, precisamente, algo de importante faltava a uma filosofia da ciência insistindo de forma unilateral sobre as questões de linguagem, de lógica das proposições e de significado. Questões como essas são, sem dúvida, fundamentais para falar com precisão; mas elas eram consideradas apenas em si próprias, no abstrato e também na intemporalidade, deixando, em geral, de lado a perspectiva das ciências tal como existem efetivamente, com suas proposições, seus procedimentos, suas interpretações e controvérsias, e fixando-se apenas em questões sobre o pensamento e a linguagem em geral.

Esta filosofia do conhecimento estava afastada demais da vida das ciências e selecionava seus problemas idealizando-os; e quando se interessava efetivamente pelas ciências e não apenas pelo pensamento científico em sua generalidade limitava-se à zona sem riscos, por assim dizer, dos conhecimentos estabelecidos, deixando de lado as ciências em gestação e que se encontram em processo de transformação. Se, por acaso, transformações e controvérsias eram evocados, eles eram imediatamente remetidos a instâncias outras que a filosofia, à psicologia dos indivíduos e à história de comunidades sociais, ambos supostos tratar de séries de acontecimentos que escapam à ciência propriamente dita e à apreensão 
da racionalidade. Isto valendo sobretudo para a filosofia da ciência da tradição anglo-saxã, na corrente analítica, que foi, como se sabe, muito influente, para o melhor e para o pior, na filosofia do conhecimento de nossa época.

A história da ciência é bastante embaraçosa para concepções que desejariam reconduzir o conhecimento científico a um tipo de sistema lógico mais ou menos fechado, remetido a categorias já fixas em relação a saberes considerados adquiridos e que poderia, a partir disto, ser analisado em si. A história da ciência ensina de imediato, com efeito, a quem se interessa por ela, não apenas que os conhecimentos se movem e se modificam sem cessar, mas que eles não são uniformes e de natureza semelhante uns em relação aos outros, se considerarmos tanto a variedade das disciplinas quanto a heterogeneidade dos sistemas de saberes nas diferentes civilizações e nas diversas épocas.

Podemos estar seguros, aliás, que a própria palavra ciência convenha a configurações de saberes e de práticas tomadas de culturas muito diferentes? Mesmo se encontramos razões convincentes para responder afirmativamente (o que é o meu caso), a questão merece ser colocada. Ela é correlata da definição daquilo que entendemos por ciência, e os estudos comparativos sobre ambientes culturais diversificados, como aqueles que vêm sendo desenvolvidos desde duas ou três décadas ${ }^{2}$, exigem, na realidade, a revisão de algumas certezas simplificadoras: daquelas, por exemplo, que, de certa maneira, fariam da ciência, no sentido que conhecemos para o mundo contemporâneo, a norma de toda ciência, deixandonos então cegos a continentes inteiros de um rico patrimônio da humanidade ${ }^{3}$.

Assinalemos, além disso, que a história da ciência, por natureza, não faz apenas o inventário das ciências adquiridas; mas ela assiste à formação de novos saberes, em geral ainda não cientes de si próprios como tais, pois a novidade, no momento em que surge, dispõe aos nossos olhos apenas o espaço daquilo que era conhecido, onde ela era ainda, propriamente falando, impensável. Para que estes conhecimentos novos tenham se tornado explícitos para nós foi preciso que as próprias estruturas de nossas representações mentais tenham sido transformadas por obra da assimilação progressiva destes.

Em suma, a história da ciência é a história dos conhecimentos que, através do espaço e do tempo, inventam-se, transmitem-se, aplicam-se, modificam-se e também se refletem sobre si próprios, por meio do pensamento crítico e filosófico e pela interpenetração com outras instâncias culturais. É sob estes aspectos diversos, não fechados e vivos, que a história da ciência nos permite apreender o que é, na sua realidade efetiva, a ciência, tanto uma das ciências em particular quanto o conjunto das ciências em suas manifestações locais e diferenciadas.

Tendo em vista este cenário, do qual será preciso detalhar pelo menos alguns traços, eu desejaria propor as seguintes reflexões sobre alguns ensinamentos filosóficos da história da ciência, focalizando-as sobre a questão da racionalidade ou do racionalismo (ligado à ciência por natureza) ao mesmo tempo considerando esta racionalidade sob a luz oferecida pela história a seu respeito. Irei concen- 
trar-me, portanto, nessa perspectiva, sobre vários aspectos das relações entre ciência, racionalidade e história, remetidas ao duplo ponto de vista da inteligibilidade e da historicidade.

\section{Dimensões da inteligibilidade racional}

Explicitemos, portanto, alguns aspectos do cenário que se nos apresenta se considerarmos os trabalhos dos historiadores e dos filósofos sobre as ciências e o pensamento científico remetendo-os à questão da inteligibilidade, isto é, da apropriação pela razão, nos pensamentos subjetivos singulares, de tal elemento de conbecimento. Sem inteligibilidade, não existe ciência, já que a ciência é uma produção humana e, bem entendido, não existe também história da ciência, já que todas as recepções, as transmissões, os remanejamentos e os novos cursos das ciências são o fruto de experiências vividas por estas mesmas subjetividades, mesmo que estivessem reunidas em "comunidades" e considerando que, de qualquer modo, elas participam de uma vida social. Não existe comunidade nem sociedade sem sujeitos individuais, a não ser que se tratem de robôs (e nem mesmo clones). A orientação das convicções intelectuais segundo "paradigmas" no sentido kuhniano ${ }^{4}$, característicos de uma época e de um contexto social, é uma imagem esquemática demais e mesmo grosseira, que parece derivada de um campo magnético orientando uma limalha de ferro de comportamento uniforme, para que ela possa aplicar-se efetivamente a pensamentos humanos que são também consciência, razão e vontade. Completamente diferente é a idéia de "campo intelectual" ou de "campo científico" proposta por Pierre Bourdieu, que deixa aos indivíduos a possibilidade de orientar-se diferentemente entre si, conservando sua capacidade de originalidade criativa ${ }^{5}$.

A história da ciência nos ensina que os conhecimentos não são transmitidos de maneira uniforme, a compreensão requisitando um conjunto complexo de disposições e atitudes, como bem sabem os docentes. Ela nos ensina também que os próprios cientistas ou pesquisadores não têm a mesma leitura de um fato, de um problema ou de uma proposição científica, ainda que estes estejam apresentados sob uma formulação racional e tão objetiva quanto possível (nós retornaremos a estas diferenças, ligadas aos “estilos científicos”).

Fixemos, por enquanto, que a racionalidade, que faz a ciência, pelo menos no sentido que ela caracteriza os conteúdos da ciência, pois é preciso levar em conta também o dado de observação ou o dado de experiência constatado (mas esta constatação também resulta de um trabalho no interior da racionalidade: crítica, procedimento, verificação etc.); que a racionalidade enfim, não é uniforme e unívoca para todos, mesmo se todos têm a capacidade da razão. Fixemos ainda que a racionalidade, no pensamento de um sujeito, não está isolada e acompanha-se da capacidade de emoção, do sentimento estético, de preocupações metafísicas, talvez religiosas, do exercício da vontade, de projetos, de escolha de valores, de uma cultura, de uma representação do mundo, segundo disposições próprias a cada indivíduo, que guiam, aliás, a "intuição intelectual” como per- 
cepção sintética imediata... Esta "intuição" à qual todos os grandes cientistas e filósofos da história do pensamento se referem, mesmo se uns e outros entendem-na de forma diferente, cada um à sua maneira, para dar conta de uma constatação sobre fatos de inteligência dos quais eles não sabem dar descrição detalhada pela análise.

Dito de outra maneira, o racional não é unívoco e transborda largamente a lógica; ele pode, nas modalidades da compreensão, apoiar-se sobre a intuição intelectual, a qual mobiliza fatores cuja complexidade resiste à análise. Ele funciona nos registros do real e do possível, implicando a consideração de dados múltiplos e de situações complexas que multiplicam as situações concebíveis a priori. E mesmo assim, apesar desta grande flexibilidade, o racional pode ser qualificado de maneira positiva e contraposto ao irracional. Ele permite definir a inteligibilidade (a inteligibilidade racional, precisamente) e constitui o motor do procedimento científico. É ele que confere a possibilidade de descrever (e de comunicar) os conhecimentos científicos adquiridos e também, pela sua própria flexibilidade, de entender que a invenção científica seja possível como resposta original e singular a uma exigência de inteligibilidade colocada de maneira particular. Esta inteligibilidade particular não está, ela mesma, fechada em sua singularidade, já que pode ser transmitida e adotada por outras sem tornar-se impessoal por este motivo: ela nunca deixa de ser o objeto de uma adaptação idiossincrática na assimilação por uma inteligência singular.'Uma das características da racionalidade é permitir a comunicação (discursiva) e o compartilhamento das explicações. A afirmação de que a razão é a coisa do mundo mais bem distribuída, certamente ainda não é uma idéia ultrapassada...

A idéia de ciência mantém, portanto, com a racionalidade, um vínculo constitucional, o mesmo podendo ser dito da atividade técnica, da qual a ciência é derivada, pelo menos na origem: a técnica, que é também um pensamento (prático) racional ${ }^{6}$, é, sem dúvida, também, como a ciência, um pensamento que de algum modo diz respeito a estética $\mathrm{e}$ às outras dimensões que nós mencionamos (o que aliás é confirmado desde a época paleolítica...). A ciência e a racionalidade mantém também um vínculo estreito com a idéia de liberdade, primeiramente pela liberdade de compreender, ou seja, o livre-arbítrio no juízo. Só pode haver conhecimento autêntico quando aceito de bom grado e, nesse sentido, a idéia de liberdade acompanha a de conhecimento intelígivel.

Podemos nos perguntar quais são, hoje em dia, as figuras desta racionalidade e investigar, ainda que ela seja freqüentemente questionada duramente através das grandes noções gerais que a sustentam como a verdade, a universalidade, a realidade (do mundo) e ainda que alguns de seus traços possam estar remodelados, se a racionalidade não comporta características invariantes, as quais perduram sob as transformações dos conhecimento e - nós o veremos - sob suas próprias ampliações. $\mathrm{O}$ abandono de antigas certezas que, pensava-se, fundamentavam-na, como a evidência divina no embasamento do cogito cartesiano, ou o 
ancoramento no mundo real pela experiência, ou sua inscrição nas estruturas de pensamento do sujeito ( $\mathrm{o}$ a priori kantiano), não a anulam por este motivo, pois ela continua presente no coração da experiência do pensamento e, particularmente, do pensamento científico. Mas ela requisita novos aprofundamentos.

Direções relativamente novas de investigações sobre a racionalidade surgem, graças às lições da história da ciência, podendo enriquecer nossas concepções sobre ela (a racionalidade, o racional) e embasá-la não como uma hipótese, opcional, mas como um fato fundador, com solidariedades inéditas em grande parte. Por exemplo, como foi lembrado anteriormente, que a racionalidade não é estranha à vontade. E ainda, que ela mantém vínculos, que apenas começam a ser inventariados, com a estética (ainda que o verdadeiro tenha sido dissociado do belo, ao qual era identificado pela Antigüidade grega). E ainda, que ela é fecunda, mais do que pela explicação, pela invenção.

Eis, precisamente, um tema relativamente novo, que poderia enriquecer de modo considerável a filosofia da ciência, o da invenção na racionalidade, da criação científica, criação de formas racionais e de conbecimentos objetivos. A invenção científica, que está ligada, evidentemente, ao crescimento das ciências, do qual é, de alguma forma, o elemento significativo que uma micro-história da ciência poderia apreender, em vista de compreender como se estabeleceram os novos conteúdos das ciências que nascem e pesquisar possíveis generalizações. Seria tentador, aqui, fazer um paralelo com a relação entre micro-história e história social na perspectiva de Carlo Ginzburg, que se interessa pelas singularidades, pelas estratégias individuais no interior de um microcosmos, para relacionálas a significações mais amplas, talvez a invariantes históricos ${ }^{7}$.

A subjetividade e a singularidade dos pensamentos e das ações humanas requisita a comunicação de uns com os outros para que eles possam inscrever-se (para nós) na história e, de forma efetiva, para que possam contribuir para fazer a história (a história simplesmente, ou a história da ciência, mas a segunda está inscrita na primeira, mesmo se ela constitui um capítulo muito particular daquela, assim como a história da arte aliás, e sem clausura, já que ela diz respeito também às próprias ciências e à filosofia ${ }^{8}$ ). Estas subjetividades e singularidades não são apagadas ou abolidas pelo desejo de objetividade, o qual caracteriza o próprio projeto de conhecimento científico: sua consideração é essencial se desejarmos que nossa concepção de conhecimento evite a depuração de um esquema abstrato, o qual viria ao encontro, aliás, da idéia de explicação universal por um "consenso social" sobre conteúdos em suma secundários, "secretados pela época", por assim dizer, sem ponto de aplicação particular significativo.

Pois trata-se, fundamentalmente, no que diz respeito à ciência, de inteligibilidade, e esta somente se realiza em indivíduos, cada um sendo particular. Esta inteligibilidade não é uniforme, pois os próprios cientistas compreendem cada um diferentemente (na maior parte do tempo e até um certo ponto) as questões discutidas, os problemas a serem resolvidos, talvez mesmo as proposições aceitas 
como resolvidas. Está claro, a partir disso, que as invenções, mesmo científicas, são sempre obras individuais, "criações" no sentido próprio, como nós o entendemos para as artes 9 . Sem o aspecto criativo, que diz respeito à diversidade de formulações e de respostas possíveis a questões ou problemas, à diversidade dos "estilos científicos" cuja caracterização é complexa (idiossincrasias pessoais, "programas epistemológicos" próprios, inscrição em "tradições científicas" distintas pela educação, experiência ou cultura $)^{10}$, não haveria invenção, nem inovação e, portanto, nem ciência como resposta à demanda de inteligibilidade.

$\mathrm{E}$, finalmente, para concluir com o cenário que se nos oferece, faríamos grande proveito do estudo das formas de racionalidade segundo outras configurações, que aparecem nas ciências de outras culturas, assim como da comunicação entre estas formas distintas e da possibilidade de traduzi-las umas na outras, por exemplo, pela sua relação à utilidade, à abstração, à prova etc. É interessante (e reconfortante) constatar que conhecimentos formulados em culturas muito distintas são, em grande parte, comunicáveis e que é possível identificá-los como pertencentes à matemática, ou à física, ou à botânica etc. Por exemplo, o que é matemático para o cientista jesuíta europeu que chega na China no século XVII tem uma correspondência no pensamento de seu interlocutor chinês, o que faz com que eles estejam conscientes de dialogar sobre um mesmo terreno ${ }^{11}$. Este reconhecimento tácito é, em si próprio, um fato de invariância e de universalidade quanto à racionalidade, de uma importância certamente considerável.

\section{Construção social e historicidade}

Os adeptos das concepções "relativistas" sobre o conhecimento que chegam, em suas versões extremas, a considerar os conteúdos científicos como vazios de sentido, invocaram eventualmente, para justificar suas concepções, as modificações da racionalidade, ou na racionalidade, ou de nossa concep̧̧ão da racionalidade. Mas que tais modificações efetivamente ocorram, como os próprios filósofos o indicaram, de Hegel a Bachelard, Granger e outros ${ }^{12}$, isto não implica que a racionalidade seja definida apenas como sendo "socialmente construída", referência feita a uma expressão que se tornou tão comum na "nova sociologia das ciências"13 que só nos resta esperar o surgimento de um título como "A construção social da razão"14; afinal acabamos de receber $A$ Social History of Truth, que quase comporta esta interpretação pelo seu próprio título ${ }^{15}$. A idéia vai bem além daquela de uma construção social de "a ciência", sobre a qual se pode argumentar, considerando a diversidade das dimensões e das funções desta última. Mas as idéias de razão e de racionalidade, ligadas ao discernimento do verdadeiro e do falso e que são a base de todo raciocínio e constituem o instrumento intelectual do pôr em relação, são mais centrais, despojadas, menos flexíveis que a idéia de ciência, a não ser que utilizemos estes termos numa acepção laxista e até "social-reducionista" como, por exemplo, "a razão do mais forte". Mas é evidente que isto seria puro sofisma e fazer um jogo de palavras ser aceito por uma demonstração. $\mathrm{O}$ tema das modificações de racionalidade merece mais 
do que tais variações sobre reflexos de superfície. Ele é fundamental para quem se interessa pelo conhecimento remetendo-o ao pensamento.

Se o examinarmos de uma maneira mais profunda, procurando caracterizar positivamente tais modificações, podemos considerá-las, na realidade, como ampliações da racionalidade, que serão possíveis de descrever e de compreender remetendo-as a argumentos de razão, apreendidos em sua própria historicidade. Não se trata, de modo algum, de saltos arbitrários de um "paradigma" a um outro que seria imposto socialmente. Um exame deste tipo, do qual esboçaremos mais adiante alguns elementos, nos assegura, apesar da derrota dos absolutos intemporais que estariam estabelecidos para sempre, da capacidade e da potência do pensamento em representar e explicar o mundo, assim como em representar-se a si próprio. Mas é conveniente, de antemão, interrogarmo-nos sobre o que pode significar, tanto no plano da história como no da ciência, aquilo que qualificamos de "construído socialmente". O sentido que deve ser eliminado desde já é aquele que negaria a significação própria dos conteúdos, nos diversos planos históricos e científicos, ou seja, a redução de qualquer nível de significação a uma simples constatação de fato social, em outras palavras, o reducionismo social ou sociológico.

Mesmo "construído socialmente", um pensamento simbólico possui seu nível próprio de significação. Seria talvez preferível, a este respeito, falar de pensamento, por exemplo, de representação "constituída" socialmente, em vez de "construída", que implica uma espécie de totalização e parece mais suscetível a favorecer os deslizes reducionistas. A noção de construção social é apenas fracamente explicativa no que diz respeito aos materiais, à arquitetura e à significação própria dada à construção em questão. Construída para as necessidades da topografia, a geometria foi, desde o seu início, uma ciência das figuras e de suas proporções, e não uma ciência da sociedade que experimentou a necessidade de medir distâncias e superfícies sobre a Terra. A verdade é que, assim que ela se encontrou formulada deste modo em referência a esta questão, a geometria definiu por este próprio meio seu objeto e este deixou imediatamente o domínio do social como tal: sua racionalidade própria, seu logos, escapavam à opinião e faziam sentido diretamente. A racionalidade assim entendida estava ao mesmo tempo consciente de si própria e determinava uma concepção precisa da ciência e da filosofia.

Quando dizemos que uma representação simbólica, uma ciência ou um elemento particular de saber foram elaborados ou construídos "na sociedade", exprimimos, na realidade, a idéia que eles o foram pelos meios e nas formas próprias do pensamento humano, no estado de existência de uma sociedade caracterizada no tempo e no espaço, e de seus saberes adquiridos e valores aceitos. Dizer que estes elementos de uma forma cultural são "construídos socialmente" é uma afirmação que traz em si própria poucos elementos de conhecimento (salvo a respeito das circunstâncias), presa entre os dois extremos da tautologia 
ou do sofisma. Em outros termos, se tal maneira de exprimir-se pode ser útil para enfatizar as relações entre estas representações e a vida social, não concluiremos por isso grande coisa sobre o que são estes próprios elementos, ainda mais quando podem ser abstraídos de significações diretamente sociais, como os dos conteúdos das ciências exatas ou da natureza, mas também, em um certo nível de profundidade, os das produções artísticas.

São estes elementos, porém, que constituem a matéria mesmo destas formas culturais. Constituídos, elaborados, construídos, por pensamentos organizados socialmente, sua significação é para ser apreendida em seu nível próprio, referente àquilo que eles designam e à maneira como eles o designam. Sendo construídos, eles não estão dados desde sempre, eles têm uma origem, transformam-se e não estão votados à eternidade ou ao absoluto. Eles são históricos.

É preciso que nos interroguemos sobre o que significa esta historicidade, posto que o próprio sentido histórico é um destes elementos de conhecimento que apareceram no universo simbólico, historicamente situado como os outros e entretanto votado, a partir do momento em que há consciência dele, a um certo grau de universalidade: tudo é histórico (quer dizer, tudo o que provém dos humanos é histórico), o que pretende ser um eco à bela definição que Marc Bloch dava da história: "a ciência dos homens no tempo"16. Tudo aquilo que diz respeito aos humanos é histórico, mesmo se eles não têm consciência disto. Parece, por exemplo, que as grandes civilizações da Índia, tão ricas filosófica e cientificamente, não possuíram o sentido histórico, o que se percebe na própria exposição de seus relatos inaugurais e de seus sistemas de pensamento. Haveria, com certeza, muito a dizer sobre o nascimento do sentido histórico e da consciência da historicidade, nas margens do Mediterrâneo e no Ocidente. Este sentido é muito mais antigo, sem dúvida, do que as pretensões arrogantes do reducionismo social que desejaria apropriá-lo sob formas empobrecidas.

Pois enfim, uma vez que o sentido histórico encontre-se afirmado, o trabalho todo sobre a historicidade está por fazer. É preciso examinar no detalhe, para uma dada sociedade (uma cultura, ou uma civilização, entendidas no sentido antropológico mais neutro possível), o conjunto das modalidades diversas que a solicitam: a organização social, a produção técnica, as ideologias e os sistemas de crenças e de valores, as formas de expressão, a estética (ver, sobre esta, as observações precedentes), os conhecimentos e os sistemas de saber e de pensamento, ou seja, a ciência e, sem dúvida, a filosofia, ou aquilo que toma o lugar destas sob um outro nome ou de fato ${ }^{17}$.

A historicidade atravessa todas as formas de pensamento e de ação humanas, e já esta diversidade deixa ver que cada forma possui suas modalidades e suas justificativas próprias, que não somente não se dissolvem neste caráter histórico, mas que tiveram seu nascimento e desenvolveram-se, constituíram-se, segundo este caráter mesmo, que presidiu à ordenação de seus "materiais" (simbólicos e concretos). Foi ao longo deste desenvolvimento que foram criados e ordenados 
os elementos (conceituais) de inteligibilidade que permitem a assimilação, num dado estágio de conhecimento, e estes próprios elementos informam aqueles do estágio seguinte, tornando-o possível. É neste sentido que o matemático Jean Dieudonné, um dos membros eminentes do movimento Bourbaki, escrevia: "Penso que não é possível compreender as matemáticas atuais se não tivermos pelo menos uma idéia sumária de sua história"18.

Em relação a isso, as matemáticas são talvez as mais visivelmente históricas das ciências exatas, pois o fio desta história pode ser seguido por um longo tempo, diferentemente da astronomia, da física, da química, da geologia, da biologia, por exemplo, cujos desenvolvimentos e remanejamentos recentes tendem a apagar, no que se refere ao seu sentido atual, sua história pregressa. O que, sem dúvida, não atenua em nada o fato de que, elas também, tanto quanto, são o fruto e o objeto de uma história, e que os conteúdos conceituais foram constituídos por obra desta história, por estratos de organizações sucessivas, que é possível recuperar sob o solo atual, como camadas geológicas a despeito das dobras efetuadas pelos movimentos (reorganizações) de terreno que sobrevieram desde então.

Portanto, uma teoria matemática (ou outra), como uma catedral, foi historicamente construída ou constituída: mas limitamo-nos, tomando consciência disto e enunciando-o, a registrar um fato, condição necessária à realização de uma possibilidade e sua matriz. Isto nos conduz apenas ao umbral desta construção, na qual devemos penetrar para apreender-lhe o sentido. Devemos ter a visão daquilo que representa, no pensamento simbólico dos homens (daquele tempo, mas também daqueles de outros tempos), esta teoria matemática, ou esta catedral. Qual é a significação dela, para eles e para nós ?

Significação para eles: nós, de nosso presente, buscamos compreender o que isto significava para os homens daquele tempo. Nós buscamos entrar nos conteúdos de sentido, entendidos segundo os sistemas de pensamento da época, nós buscamos compreender na historicidade, estabelecendo por este próprio meio o que é a disciplina (a ciência) histórica, indo além do relato descritivo. Pois trata-se de compreender, isto é, de estabelecer uma ponte entre nós e esta época, relativa a este elemento de representação abstrato ou arquitetônico, para tentar apreender o pensamento dos seres humanos daquela época, pelo menos dos criadores que construíam e viviam estas formas, que as concebiam (eles mesmos inseparáveis dos contemporâneos que as recebiam ou as habitavam). Trata-se de apreender este pensamento em si próprio, segundo a "sistemática" de suas significações próprias, sem projetar sobre ele nossas exigências ou nossos critérios de inteligibilidade e de significância. Este é o problema-chave do método histórico, sobre o qual voltaremos a falar.

Significação para nós: entendo-o da seguinte forma. Em relação às formas de pensamento (matemática, no caso indicado), de expressão, ou de técnica (arquitetônica, por exemplo) que nós conhecemos, em nossa época, qual é o elo (se houver algum, e é difícil negar durante muito tempo que haja um) que corre 
destas formas antigas às formas atuais e, sobretudo, qual nova significação as formas atuais, que eram impensáveis na época antiga, conferem a estas primeiras realizações? Ou seja, nós buscamos entender como nossos conteúdos de sentido, novos em relação àqueles que os precederam, tornaram-se possíveis. Nós buscamos compreender, por um processo retrospectivo, como estas formas que são significativas para nós e que correspondem às nossas racionalidade e estética atuais, puderam ser efetivamente constituídas. Isto é, buscamos compreender não somente as condições de possibilidade, mas a realização efetiva de tais possibilidades, nestes conteúdos de conhecimentos ou formas de expressão que constituem no presente nosso universo inteligível e significativo. O conhecimento do passado, em sua significação própria, permite-nos entender a possibilidade e as modalidades de constituição de nosso conhecimento atual e, desta forma, sua significação, pelo menos em parte.

Um procedimento deste tipo, que constitui propriamente o procedimento histórico (história social, história da ciência, das técnicas, das artes, das idéias), estabelece de antemão a legitimidade do interesse pelos conteúdos de sentido, para qualquer um dos "objetos" em questão e correspondentes disciplinas (mesmo que suas definições e fronteiras fossem móveis e flutuantes durante o curso da história).

Evoquei, sobretudo, conhecimentos, técnicas ou artes, mas diríamos o mesmo de concepções sociais, de crenças e de valores, morais, éticos ou espirituais. Toda forma simbólica e todo sistema de tais formas suscita o olhar histórico e coloca o problema da relação da historicidade e dos conteńdos de sentido. Eu me limitarei a seguir a considerar o conhecimento, e singularmente o conhecimento científico, mas é evidente que a história é una, como o pensamento, sede das ações humanas que estão inscritas na história e a tecem.

\section{Historicidade dos conteúdos de sentido}

Não se pode representar o fluxo histórico em tempo real ou em tamanho natural. É conhecido aquele conto de Jorge Luis Borges no qual um geógrafo minucioso, tomado por uma preocupação de realismo integral, propõe-se a estabelecer o mapa de uma certa região da superfície da Terra da forma mais fiel possível: quando concluído o mapa acaba por recobrir exatamente a extensão representada. $\mathrm{O}$ mapa tem a própria dimensão do terreno. Por outro lado, como escrevia Henri Poincaré, o cérebro do homem, que se situa dentro do Universo, não poderia conter em si mesmo todos os elementos do Universo ${ }^{19}$. A representação da realidade, da realidade do mundo natural ou da realidade histórica, não pode coincidir com esta realidade (em primeiro lugar, porque ela é de natureza simbólica, transcrita em forma de signos, de palavras significando conceitos ou de imagens que têm, no pensamento, a função de representar esta realidade, mas que são de uma natureza totalmente diferente). Os fatos que servirão de base às nossas representações não podem ser exaustivos e devem ser escolhidos, na história como na ciência, pela significação de seus conteúdos. 
Neste sentido, Marc Bloch escrevia, na Apologie pour l'histoire, ou Métier d'historien: "Face à imensa e confusa realidade, o historiador é necessariamente levado a recortar dentro dela o ponto de aplicação particular de seus instrumentos; em conseqüência, a fazer uma opção em seu interior que, com certeza, não será a mesma [de um outro especialista cujo objeto seria outro, um biólogo, por exemplo], e que será uma opção de historiador”;“o que é”, acrescenta ele, "um verdadeiro problema de ação", que persegue o historiador durante todo o curso de suas pesquisas ${ }^{20}$.

É também porque o olhar posterior é útil e permite fazer $a$ história e não (pequenas) histórias, sem significação profunda. Se ele é útil e necessário em história, este olhar retrospectivo não o é menos, com certeza, na história da ciência, permitindo considerar para uma mesma época elementos (fatos de saber) cujo elo não podia ser percebido no momento, mas cuja reunião se mostra em seguida estruturalmente significante para uma dada ciência e permite caracterizar factualmente, no tempo histórico, o progresso de um capítulo do conhecimento científico.

Poderíamos dar muitos exemplos disto, cuja análise epistemológica seria significativa, especialmente a partir da elaboração das ciências modernas, no século XVII. As leis de Kepler do movimento dos planetas e a lei de Galileu da queda dos corpos pareciam sem elo entre si até que Newton as reunisse sob uma teoria explicativa comum, com as leis gerais do movimento e a hipótese da atração universal de gravitação. A mesma lei da queda dos corpos de Galileu, com a igualdade das acelerações de quaisquer corpos a uma altura dada e seu enunciado da relatividade do movimento, que são tratadas em duas obras diferentes, encontram sua síntese comum na teoria da relatividade geral de Einstein (que reúne a igualdade das massas inercial e gravitacional dos corpos, transcrição da lei de Galileu, com o princípio de relatividade estendido aos movimentos acelerados). Etc.

Exemplos deste tipo mostram bem o que ganhamos levando plenamente em conta a historicidade dos conhecimentos: oferecemo-nos desta maneira os meios de compreender o movimento de sua constituição progressiva, da formação das novas significações que eles engendram. Quando falamos de historicidade dos conteúdos (de uma ciência), não é para dizer que a historicidade dissolveria os conteúdos mas, ao contrário, para dizer que ela tece a forma deles com materiais que lhe foram dados e cuja natureza (de conteúdos conceituais, conteúdos de pensamento) resiste a toda redução externa (social). Parece legítimo dizer que, inversamente, só há historicidade em função dos conteúdos, já que é a compreensão do modo pelo qual estes se constituiram que permite entender, precisamente, sua historicidade.

Poderíamos transcrever esta observação sobre os conteúdos e a historicidade em termos de relações entre a epistemologia (entendida como o estudo das ciências segundo os conteúdos de sentido) e a história da ciência (o estudo das ciências segundo o fluxo histórico), sintetizada na conhecida fórmula ${ }^{21}$ : "A epistemologia sem história da ciência é vazia, a história da ciência sem epistemologia é cega". 


\section{A inteligibilidade sob o signo da racionalidade}

Do ponto de vista da história, as formas simbólicas correspondentes à diversidade de pensamentos e de ações humanas e, em particular, para a história da ciência, aquelas que correspondem a conhecimentos científicos, constituem um dado factual que se trata de compreender, isto é, de interpretar ou de explicar. Esta compreensão supõe a possibilidade de uma comunicação, mesmo que indireta e parcial, entre estas formas do passado e aquelas que habitam o sujeito presente e dirigem seu olhar. $\mathrm{O}$ conhecimento ou a ciência da história faz ele mesmo parte deste "olhar" atual, informado daquilo que conhece mas ao mesmo tempo sabendo descentrar-se ou, pelo menos, consciente desta necessidade. Conceber estas formas como produzidas no passado implica este olhar, senão "científico" no sentido próprio (o que implicaria precisar que tipo de ciência é a história), pelo menos de visada objetivante: compreender o que existia, o mais próximo possível do que aquilo era, isto é, da significação que aquilo tinha então para os sujeitos e os protagonistas deste conhecimento e, com este objetivo, procurar instalá-lo no sistema antigo de significação reconstituído. É isto que queremos dizer quando falamos, para um conhecimento histórico, de compreender, de interpretar, de explicar... Trata-se de estabelecer o sistema de compreensão, historicamente pertinente, no seio do qual os elementos simbólicos portadores de conteúdos significativos, por exemplo os conceitos, conferem-se sentido uns aos outros através de suas relações e fazem sentido no corpo mais amplo de conhecimentos da época. Este sistema pode então ser posto em relação com o nosso do qual teremos sabido nos descentrar, ou com outros sistemas de conhecimento correspondentes a etapas intermediárias no curso da história.

A própria noção de explicação passa por transformações à medida que se lida com exigências diferentes para o conhecimento e que se criam novas exigências. São as próprias referências da explicação que mudam com outras demandas de inteligibilidade. Ver, por exemplo, a ruptura entre a inteligibilidade cartesiana e a inteligibilidade newtoniana (de ações concebidas por choques a ações segundo a atração); e a superação desta última (que se atinha a uma visão neoplatônica das relações entre a matemática e a natureza) pela mudança de estatuto da própria atração após Newton. Esta tornou-se, nas mãos de seus sucessores (D’Alembert, Euler, Laplace...), um princípio de explicação física para a teoria do sistema solar baseada sobre a solução (aproximada) do problema dos três corpos. Em seguida, com a idéia de campo de propagação progressiva, uma nova etapa da racionalização destes fenômenos foi alcançada, fenômenos dos quais a teoria da relatividade de Einstein, conceitualmente mais simples e mais homogênea e, portanto, mais racional, deveria mais tarde fornecer uma inteligibilidade mais completa.

A análise detalhada de tais casos nos mostraria efetivamente como se constitui e se transforma, na história das idéias, a inteligibilidade racional;e como, em particular, o que vem, mesmo que parcialmente, da experiência, pode encontrarse assimilado no pensamento pela sua transformação em racional. 


\section{As extensões do racional}

De uma certa maneira, a formalização matemática da física permite superar a alternativa do empírico e do racional. Através da expressão matemática (teórica), o conhecimento dos novos fenômenos que a teoria explica ou antecipa, mesmo provindo da experiência do mundo exterior, insere-se no espaço do conhecimento racional. Pois este empírico é assimilado em formas que pertencem ao racional: assim como, segundo o que vimos mais acima, fatos de observação suficientemente gerais são erigidos pelo pensamento em princípios que podem ser expressos como axiomas, em relação aos quais eles têm a função referencial e organizadora. É assim que procede, de uma forma geral, a fisica teórica, que se caracteriza ao mesmo tempo pela sua expressão matemática e sua fidelidade à especificidade dos fenômenos ${ }^{22}$. Diferentemente da física matemática entendida no sentido restritivo de sua pura formalização, que funciona apenas segundo a racionalidade matemática (interna por assim dizer, mas suscetível, ela também, de extensões), a física teórica constitui sua forma (matematizada) através da assimilação racional de fenômenos empiricamente dados. Ou seja, o racional ampliou-se graças à assimilação do empírico, ou ainda, é através da experiência do mundo natural que se desenvolve o teórico e o inteligível e que aumenta o espaço do racional. O racional funciona aqui, em suma, de forma orgânica, permanecendo ele mesmo, ao mesmo tempo em que modifica suas estruturas, aumentando suas capacidades, sem se dissolver no empírico do qual ele se nutre.

A matematização da física (mais precisamente: de tal teoria física), justificada pelas propriedades dos conceitos e das grandezas, adequadamente definidas, que permitem caracterizá-la ${ }^{23}$, torna-se assim ela mesma princípio de explicação, como se vê de uma forma particularmente nítida e exemplar ao longo da história dos três últimos séculos, com a "analitização" de diversos domínios da física pelo cálculo diferencial e integral, legitimada apenas na medida em que as grandezas e os princípios que correspondem à especificidade dos fenômenos físicos foram formulados exatamente ${ }^{24}$. Um tal "princípio de explicação" dá conta de maneira ao mesmo tempo analítica e sintética das relações as mais precisas entre os conceitos e as grandezas que tecem as propriedades do mundo físico e exprimem sua unidade subjacente.

Diversas questões epistemológicas, mas também de natureza ontológica ou metafísica, ficam em suspenso. Mencionarei, no rol das questões epistemológicas ou oriundas da filosofia do conhecimento, primeiro a diversidade dos epistemas para as diversas ciências (por exemplo, a biologia, com modos de racionalidade em parte diferentes dos da física) e a necessidade de opor-se aos reducionismos injustificados; em seguida a não-univocidade da racionalidade, considerando um dado problema científico, questão que é a do transbordamento do lógico pelo racional, à qual responde a consideração da variedade dos "estilos científicos" e dos "programas epistemológicos", e a "liberdade lógica" do trabalho do pensamento, cara a Poincaré e a Einstein, que lhes é subjacente ${ }^{25}$. 
$\mathrm{E}$, ainda, a questão das interpretações e os efeitos da interpretação sobre o pensamento dos conteúdos, que foram exemplificadas em nossa época, como se sabe aliás, por teorias como a mecânica quântica ou a evolução darwiniana. Toda a questão da interpretação da mecânica quântica, nas suas variantes as mais diversas, diz respeito à preocupação de estabelecer esta ciência sobre uma base de inteligibilidade racional; mas as opiniões diferem sobre o que deve ser esta base ${ }^{26}$. Em relação a isto, a questão da exigência de racionalidade encontra, mas de uma forma naturalmente pouco clara no início, aquela das ampliações da racionalidade. Eu a entendo no sentido de uma ampliação daquilo que é admitido como explicação racional para alguma coisa existente, sejam figuras geométricas, números, ou entidades físicas ou de outra natureza.

Quanto às questões ontológicas, assinalarei apenas que a ampliação do campo das explicações e da racionalização não anula o domínio obscuro que reside, cambiante mas irredutível, no embasamento de todo conhecimento (constatação pascaliana ou "relatividade da ontologia" no sentido de Willard Quine ${ }^{27}$ ).

Em relação às questões metafísicas, irei ater-me a uma delas, pascaliana também (ligada, aliás, à anterior), aquela de nossa ignorância em relação ao nosso conhecimento, questão que está no horizonte de toda evocação do inteligível. Se o "livro do conhecimento" está destinado a ser sempre finito, se bem que ele não cesse de aumentar, e a despeito de nossos esforços para aumentá-lo, não deveríamos considerar que a medida de nossas questões seria melhor avaliada num "livro de nossa ignorância"? Pois poderia parecer que, sabendo o que sabemos, nós mediríamos mais o grau de nossa ignorância do que o de nosso conhecimento. Mas a isto será respondido que o livro de nossa ignorância é mais incerto ainda, podendo ser visto tanto como quase vazio ou como infinito. É que nossa ignorância, da forma como temos consciência dela, sempre é relativa àquilo que conhecemos. Pode nos parecer, às vezes, como foi o caso de alguns físicos do fim do século XIX (e é também o caso de alguns físicos do final do século XX, sem falar dos biólogos...), que o domínio das questões não resolvidas de tal ciência diminui a cada dia como chagrém ${ }^{28}$ : a física, diziam eles, explica daqui em diante praticamente tudo e comporta apenas dois pontos obscuros, a ausência de vento de éter e a lei da irradiação térmica. Ora, estes dois fenômenos, precisamente, longe de serem de alcance limitado e circunscritos pelas teorias da física, assinalavam seus abismos profundos que determinaram as duas "revoluções científicas" ocorridas em física no século XX, as da relatividade e dos quanta.

Nós não temos idéia do que o futuro nos reserva em relação às transformações dos próprios fundamentos de nosso conhecimento. Por mais garantidos que os imaginemos, eles sempre poderão, em princípio, ser modificados, pois nenhum elemento de suas bases é intangível, já que todos comportam uma parte de arbitrário relativa ao fato de serem produtos do espírito humano, formas simbólicas. É por este motivo que nunca concluiremos a busca das razões das razões e ainda é Pascal que reencontramos: o livro de nossa ignorância é um 
infinito insondável. Apesar disto avançamos, a meio caminho entre estas duas ignorâncias, a quase nula e a infinita, ou entre estes dois conhecimentos, um irrisório e o outro imenso (em dois momentos subjetivos de nosso juízo), com, nestes intermédios, o sentido do inteligível como provisão e a consciência da historicidade como guia.

\section{Inteligibilidade da historicidade}

Nós buscamos esclarecer a questão da relação entre duas instâncias da atividade de conhecimento, a inteligibilidade racionale a historicidade, freqüentemente consideradas equivocadamente como contraditórias ou divergentes. Mas nós deixamos de lado até aqui a seguinte questão, que parece mais espinhosa ainda: como a consciência da historicidade dos conhecimentos justapõe-se ao conteúdo de verdade dos conhecimentos? Admitiremos que estes conteúdos de verdade são relativos, mas que a idéia de verdade, sem conotação de absoluto, guarda porém uma função de regulação que não é ilusória, ou seja, que uma verdade relativa pode ser oposta a uma falsidade absoluta. Nós o admitiremos sem avançar mais aqui nos problemas filosóficos que estas noções suscitam. É desnecessário dizer, portanto, que a inteligibilidade trata de tais conteúdos de verdade (relativa). O que podemos dizer sobre uma questão destas, colocandonos apenas na perspectiva da exigência de historicidade?

Para que as diferentes representações-explicações propostas ao longo do tempo continuem inteligíveis, de uma maneira ou de outra, ainda que muito imperfeitamente, foi e é necessário que modificações tenham sido e sejam possíveis. Ou seja, que a invenção de novas formas de representação tenha sido e continue sendo possível, e que uma compreensão das formas passadas também continue possível depois delas, num outro universo de significações, como por exemplo, o nosso: e se nós quisermos ser, por pouco que seja, historiadores, é preciso que conquistemos a capacidade de ultrapassar o sentido imediato que estas formas do passado poderiam ter para nós, por projeção, e esforçar-nos na compreensão de um sentido próprio a este passado mesmo. E, para tal, é de fato preciso que, em primeiro lugar, como apontava Marc Bloch, nós mesmos tenhamos experienciado o conhecimento de nosso próprio presente. $\mathrm{O}$ conhecimento do presente ajuda a conhecer o passado; ele é, pode-se até dizer, sua condição primeira $^{29}$.

E é preciso também que a compreensão destas formas passadas de conhecimento tenha um sentido, que haja um tipo de continuidade mínima, que os dois universos tenham uma medida comum, sob sistemas de representação diferentes. A história das relações entre conhecimentos em sucessão no tempo ${ }^{30} \mathrm{e}$ especialmente aquela das transmissões culturais, em particular das transmissões dos saberes científicos, proporciona a este respeito uma rica colheita de fatos, a despeito de todas as nossas incógnitas sobre várias situações complexas e passados longínquos ${ }^{31}$. No debate de certos filósofos e historiadores das ciências sobre a incomensurabilidade dos sistemas conceituais e teóricos, de Kuhn a 
Feyerabend e outros ${ }^{32}$, estes esqueceram-se apenas de uma coisa, é que a transmissão existiu e existe, e com ela a comunicação, que pedia alguma "medida" comum, na prática do trabalho dos cientistas, e que isto são fatos históricos. Fatos empíricos talvez, mas que, como fatos, pedem para serem compreendidos, assim como aqueles dos quais falamos para a história da ciência.

Ou seja, nós colocamos necessariamente através disso a inteligibilidade da historicidade. Pela atenção a estes fatos da história e pelas lições de sua análise, a questão de uma "incomensurabilidade" mostra ser apenas formal, colocando-se a respeito de axiomáticas sobre corpos (ou estruturas) de proposições fixas; se ela pode ter seu interesse neste nível, ela não é pertinente do ponto de vista histórico, onde nos esforçamos, no trabalho de pesquisa, de ultrapassar uma teoria que apresenta dificuldades, da qual, porém, partimos, ainda que para forçá-la... Poderíamos multiplicar os exemplos, considerando situações reais que foram objeto de experiências vividas, relativas tanto a trabalhos científicos que conduziram a descobertas ou invenções, quanto a situações de recepção de novas teorias ou ainda a remanejamentos teóricos. As descontinuidades no pensamento, assim como nas ações e nos acontecimentos, sempre se destacam sobre um fundo de continuidade.

A lição dos fatos da história a este respeito (fatos da história da ciência) é, ao contrário da tese da incomensurabilidade, que existe uma medida comum entre conhecimentos em seqüência histórica inscritos em sistemas de pensamento diferentes e, portanto, correspondentes a conteúdos conceituais distintos, apesar da dificuldade de dar conta da passagem de um para outro, ou do diálogo entre eles; poderá, aliás, ter sido o caso de uma tradução apenas parcial e transformada. E podemos então nos perguntar se isto não seria decorrente, precisamente, da racionalidade e da consciência desta racionalidade. Pode-se objetar, sem dúvida, que a racionalidade da ciência não é uma através das disciplinas e dos objetos, das épocas e das culturas; e que ela nem mesmo é unívoca para uma dada ciência e objeto de ciência, já que ela admite variantes quando esta ciência está em formação ou em transformação; e que a própria racionalidade é modificada e se modifica ao longo da história ${ }^{33}$. Mas está claro que a objeção não implica impossibilidade, quando, pelo contrário, ela dilata os elementos dos sistemas tomados na comparação, dando-lhes mais jogo, tornando seu agenciamento efetivo menos rígido aos nossos olhos de observadores do passado.

Podemos falar, com certeza, de historicidade da própria racionalidade: mas será preciso definir o que isto significa, pois palavras deste tipo, mesmo correspondendo a realidades, não são, bem entendido, sésamos abertos para todas as interpretações não fundadas, talvez fantasistas, que incluem as reduções e as dissoluções. Pois é, exatamente, porque uma comunicação é constatada, como uma matéria de fato, e que ela é, portanto, de direito possível, sejam quais forem suas transformações (e as traições - naturais - de suas traduções) e também suas limitações, que nós podemos continuar falando de racionalidade como algo que 
designa um núcleo mais profundo que os próprios conteúdos de conhecimento, que os torna possíveis e os constitui, e que nós provavelmente estamos longe de ter esgotado; núcleo graças ao qual, em todo caso, nós podemos ter acesso, a partir de nosso presente, a uma compreensão sempre perfectível do passado ou dos alhures contemporâneos.

Quanto ao futuro, que em geral nos é amplamente imprevisível, se ele revela-se progressivamente para nós, na velocidade mesma (ou aproximada) de suas realizações, é na oportunidade da elaboração de novos esquemas de compreensão que se fundamentam sobre a racionalidade e sobre sua capacidade de ampliação, solicitada pelas nossas exigências sucessivas de inteligibilidade, e que permitem conceber (racionalmente) o que era até aqui ainda impensável.

Nossa consciência da historicidade estabelece a exigência de sua inteligibilidade, e ela a estabelece segundo condições epistêmicas que são aquelas específicas à história como disciplina. Por exemplo, segundo uma concepção própria do tempo dos homens em suas sociedades e culturas, que é o mesmo da consciência histórica, o tempo dos distanciamentos e dos amadurecimentos. "Realidade concreta e viva restituída à irreversibilidade de seu impulso", escrevia Marc Bloch, "o tempo da história, ao contrário [daquele das ciências da medida], é o plasma mesmo onde estão imersos os fenômenos e como que o espaço de sua inteligibilidade" ${ }^{34}$. Esta consciência do tempo da história suscita a idéia de levar em conta as modificações de significação, tanto na história como na história da ciência. Convidando os historiadores a evitar o erro "de confundir uma filiação com uma explicação", Marc Bloch lembrava-os que as idéias que contribuem para formar outras, quer se trate do regime feudal ou das idéias da Revolução, ao passar de um meio para outro, ou de uma geração para outra, são transformadas, adaptadas às condições novas, sociais ou intelectuais ${ }^{35}$.

A denúncia do grande historiador, da "filiação" tomada por uma explicação, vale para a "construção social" segundo o que dissemos dela no início: ela não resolve o problema de saber porquê e como isto foi transmitido ou construído, ou seja, a questão das significações e dos conteúdos, mesmo ligados às circunstâncias. "Nunca [...] um fenômeno histórico é explicado plenamente fora do estudo de seu momento", escrevia ainda Marc Bloch ${ }^{36}$. Isto significa, para nós, que a historicidade se opõe aos algoritmos das reconstituições intemporais, e isto vale em particular para a história da ciência: nem reducionismo social nem algoritmo racional intemporal deram e darão conta da ciência que se inventa no pensamento humano inscrito na história.

\section{Notas}

l O texto original em francês, "Intelligibilité rationelle et historicité", retoma no essencial, atualizando-a, uma versão mais longa, publicada sob o título "Intelligibilité rationelle et historicité (Science, rationalité, histoire)” em: Juan José Saldãna (ed.), 
"Science and Cultural Diversity. Filling a Gap in the History of Science", Cadernos de Quipu 5, México, 2001, pp. 59-95.

2 Cf., por exemplo, Jami, Moulin e Petitjean, 1992; Habib e Raina, 1999 e referências bibliográficas em Paty, 1999b.

3 Cf. Paty, 1999a e b.

4 Kuhn, 1962.

5 Bourdieu, 1966, 1976 e 2001.

6 Ver, sobre o desenvolvimento da fabricação dos instrumentos e aquele correlato do pensamento, as obras daqui em diante clássicas de André Leroi-Gourhan (LeroiGourhan, 1964 e 1971).Ver também Calder, 1961. Sobre a filosofia da técnica, ver Simondon, 1989 [1958].

7 Ginzburg, 1989; Levi, 1991e Dosse, 1999, p.74.

8 Paty, 1990.

9 Sobre a criação científica, ver Paty, 1999e.

10 Sobre estas noções, ver especialmente Granger, 1988 [1968]; Hacking, 1992 e Paty, 1990,1993 e 1996.

11 Ver Jami, 1992 e outros trabalhos do mesmo autor. Cf. Paty, 1997 e 1999a e b.

12 Hegel, 1965; Bachelard, 1949 e Granger, 1955.

13 Ian Hacking fez seu inventário recentemente em seu livro The Social Construction of What?(Hacking, 1999).

14 Em inglês no original (nota do tradutor).

15 Shapin, 1994.

16 Bloch, 1949, p. 4.

$17 \mathrm{O}$ fato de estas noções não serem reflexivas em uma dada cultura não significa, por este motivo, que elas estejam ausentes.

18 Dieudonné, 1987, p. 10.

19 Poincaré, 1918 [1908], cap. 2, p. 20.

20 Bloch, 1949, p. 2.

21 Transformada desde Kant por, entre outros, Carnap, Einstein, Feyerabend...

22 Paty, 1994 e 1999c.

23 Paty, 1998b e 2001 h.

24 Cf. Paty, 1994.

25 Poincaré, 1902 e 1905; Einstein, 1946; Paty, 1993, cap. 9 e 1999e.

26 Paty, 2000.

27 Pascal, 1670 e Quine, 1969.

28 "Peau de chagrin" em francês. Segundo Houaiss, "variedade de couro granulado...usado em marroquinaria e encadernação". Referência a um conto de Balzac no qual a pele de um cordeiro encolhe. (nota do tradutor)

29 Bloch, 1949.

30 Por exemplo, a física de Newton e a de Einstein: cf. Paty, 1987. 
31 Cf., por exemplo, Needham, 1954,1969, 1974 e 1993; Rashed e Morélon, 1997; Habib e Raina, 1999; Thapar, 1999 e Paty, 1999b.

32 Kuhn, 1962 e 2000 e Feyerabend, 1981.

33 Granger, 1967 [1955].

34 Bloch, 1949, p. 5.

35 Idem, p. 7.

36 Idem, p. 9.

\section{Referências}

BACHELARD, Gaston. Le rationalisme appliqué. Paris, Vrin, 1949.

BLOCH, Marc. Apologie pour l'histoire ou Métier d'historien, Cahiers des Annales, 1949 (Manuscrito original: 1941. 1 ’a publicação, póstuma, preparada por Lucien Febvre); nova edição crítica preparada por Etienne Bloch e Jacques Le Goff, Paris, Armand Colin, 1993 [1949].

BOURDIEU, Pierre. "Champ intellectuel et projet créateur". Les Temps modernes, n. 246, 1966, pp. 865-906.

"Le champ scientifique". Actes de la recherche en sciences sociales, n. 2/3, 1976, pp. 88-103.

. Les règles de l'art. Genèse et structure du champ littéraire. Paris, Minuit, 1992.

Science de la science et réflexivité. Paris, Raisons d'Agir, 2001.

CALDER, Richtie. Man and his techniques, 1961. Tradução francesa de Henri Delgove, L'homme et ses techniques. Paris, Payot, 1963.

CASSIRER, Ernst. Die Philosophie des symbolischen Formen, 1923, 1924, 1925. Tradução francesa de Ole Hansen-Love e Jean Lacoste, La philosophie des formes symboliques. Paris, Minuit, 3 vols., 1972.

DIEUDONNÉ, Jean. Pour l'honneur de l'esprit humain. Paris, Hachette, 1987.

DOSSE, François. L’histoire ou le temps réfléchi. Paris, Hatier, 1999 (Optiques).

FEYERABEND, Paul. Philosophical Papers, 2 vols. Cambridge, Cambridge University Press, 1981.

GINZBURG, Carlo. Miti, emblemi, spie: morfologia e storia. Torini, 1986; Tradução francesa, Mythes, emblèmes, traces. Paris, Flammarion, 1989.

GRANGER, Gilles-Gaston. La raison. 9 ed., Paris, Presses Universitaires de France, 1989 [1955] (Que sais-je?).

Essai d'une philosophie du style. Paris, Armand Colin, 1968; reed. Paris, Odile Jacob, 1988.

HABIB, S. Irfan e RAINA, Dhruv (eds.). Situating the History of Science: Dialogues with Joseph Needham. New Delhi, Oxford University Press, 1999.

HACKING, Ian. "Style' for Historians and Philosophers", Studies in History and Philosophy 23, 1992, pp. 1-20. 
. The Social Construction of What? Cambridge (Mass.), Harvard Universiy Press, 1999.

HEGEL, Georg Wilhelm Fiedrich. La raison dans l'histoire (Introduction aux leçons sur la philosophie de l'histoire), nova tradução, introdução e notas de K. Papaioannou, Paris, Le monde en 10/18, 1965.

JAMI, Catherine. "Western Mathematics in China, Seventeenth Century and Nineteenth Century”. Em JAMI, MOULIN E PETITJEAN, 1992, pp. 79-88.

JAMI, Catherine; MOULIN, Anne-Marie e PETITJEAN, Patrick (eds.). Science and Empires. Dordrecht, Kluwer,1992.

KUHN, Thomas. The Structure of Scientific Revolutions. 2 a ed., Chicago, The University of Chicago Press, 1970 [1962].

. Dogma contra critica. Mondi possibili nella storia della scienza, con due lettere di Paul K. Feyerabend, a cura di Stefano Gattei. Milano, Raffaello Cortina editore, 2000.

LEROI-GOURHAN, André. Le geste et la parole, 2 vols. Paris, Albin Michel, vol. 1: Technique et langage, 1964; vol. 2: La mémoire et les rythmes, 1965.

. Evolution et techniques, 2 vols. Paris, Albin Michel, vol. 1: L'homme et la matière (1 ${ }^{\mathrm{a}}$ ed., 1943), nova versão, 1971. Vol. 2, Milien et techniques, 1971.

LEVI, Giovanni. "On Micro-history"; trad. brasileira "Sobre a micro-historia”. Em BURKE, 1991, trad. br., 1992, pp. 133-161.

NEEDHAM, Joseph. Science and Civilisation in China. Cambridge, Cambridge University Press, 7 vols. em 34 tomos, 1954-.

The Great Titration, 1969; tradução francesa de Eugène Jacob, La science chinoise et l'Occident (Le Grand Titrage). Paris, Seuil, 1973.

. [1974]. La tradition scientifique chinoise (coletânea de artigos traduzidos para o francês), Paris, Hermann, 1974.

Dialogues des civilisations Chine-Occident. Pour une histoire acuménique des sciences. Coletânea de artigos idealizada por G. Métaillé. Paris, La Découverte, 1993.

PASCAL, Blaise. Pensées. Em B. P., Oeuvres complètes, Prefácio de Henri Gouhier, apresentação e notas de Louis Lafuma, Paris, Seuil, 1963 [1670].

PATY, Michel. “Einstein et la pensée de Newton”. La Pensée, n. 259, 1987, pp. 17-37.

. L'analyse critique des sciences, ou le tétraèdre épistémologique (sciences, philosophie, épistémologie, histoire des sciences). Paris, L'Harmattan, 1990.

. Einstein philosophe. La physique comme pratique philosophique. Paris, Presses Universitaires de France, 1993.

"Le caractère historique de l'adéquation des mathématiques à la physique". Em GARMA, Santiago; FLAMENT, Dominique e NAVARRO, Victor (eds.). Contra los titanes de la rutina. Contre les titans de la routine. Madrid, Comunidad de Madrid/ C.S.I.C., 1994, pp. 401-428.

. "Remarques sur la production sociale des sciences et la question de la vérité". Em MALET, Emile e LE BRAS, Hervé (eds.), Science et démocratie. Penser le XXIè siècle. Paris, Editions Passages, 1996, pp. 185-219.

"L'idée d'universalité de la science et sa critique philosophique et historique". Em ARBOLEDA, Luis Carlos e OSORIO, Carlos (eds.). Nacionalismo e 
internacionalismo en la historia de las ciencias y la tecnología en America latina, Memorias del IV Congresso Latino-Americano de Historia de las Ciencias y la Tecnología. Cali (Colombia), Universidad del Valle, 1997, pp. 57-89. Egalement, Asclepio (Madrid), 49 (2), 1997, pp. 5-43.

. "La philosophie et la physique". Em MATTÈI, Jean-François (ed.). Le Discours philosophique, vol. 4 de l'Encyclopédie philosophique universelle. Paris, Presses Universitaires de France, 1998, cap. 123, pp. 2104-2122.

. "L'universalité de la science. Une idée philosophique à l'épreuve de l'histoire". Mâat. Revue Africaine de Philosophie, n. 1, abr. 1999a, pp. 1-26. Trad. inglesa., "Universality of Science: Historical Validation of a Philosophical Idea em Habib e Raina”, 1999, pp. 303-324.

. "Comparative history of modern science and the context of dependency", trad. do francês por Nicholas Flay, Science, Technology and Society. An International Journal Devoted to the Developping World. Sage Publications, New Delhi, 4, 2, 1999b, pp. 171-204.

"La place des principes dans la physique mathématique au sens de Poincaré". Em SEBESTIK, Jan e SOULEZ, Antonia (eds.). Actes du Colloque France-Autriche Paris, mai 1995, Interférences et transformations dans la philosophie française et autrichienne (Mach, Poincaré, Duhem, Boltzmann), Fundamenta philosophic. Paris, Nancy/éd. Kimé, 3 (2), 1998-1999c, pp. 61-74.

"La création scientifique selon Poincaré et Einstein". Em SERFATI, Michel (ed.). La recherche de la vérité, Coll. L'écriture des Mathématiques, Paris, ACL-éditions du Kangourou, 1999e, pp. 241-280. Tradução portuguesa: “A criação científica segundo Poincaré e Einstein”. Trad. Sérgio Alcides, Estudos Avançados, 15, n 41, jan.abr. 2001c, pp. 157-192.

. «Interprétations et significations en physique quantique». Revue Internationale de philosophie, n. 212, 2000, pp. 17-60.

"La notion de grandeur et la légitimité de la mathématisation en physique". Em ESPINOZA, Miguel (ed.). De la science à la philosophie. Hommage à Jean Largeault. Paris, L'Harmattan, 2001h, pp. 247-286. Versão inglesa: “The idea of quantity at the origin of the legitimacy of mathematization in physics”. Em GOULD, Carol (ed.) Constructivism and Practice: Towards a Historical Epistemology. Lanham (Md.,USA), Rowman \& Littlefield, 2003h, pp. 109-135.

POINCARÉ, Henri. La science et l'hypothèse. Paris, Flammarion, 1968 [1902].

. La valeur de la science. Paris, Flammarion, 1970 [1905].

Science et méthode. Paris, Flammarion, 1918 [1908].

QUINE, Wllard V. Ontological Relativity and Other Essays. New York, Columbia University Press, 1969; tradução francesa de Jean Largeault, Relativité de l'ontologie et autres essais. Paris, Aubier-Montaigne, 1971.

RASHED, Roshdi e MORÉLON, Régis (eds.). Histoire des sciences arabes, 3 vols. Paris, Seuil, 1997.

SHAPIN, Steven. A Social History of Truth. Civility and Science in Seveteenth Century England. Chicago, University of Chicago Press, 1994.

SIMONDON. Du mode d'existence des objets techniques. Paris, Aubier, 1989 [1958]. 
THAPAR, Romila. "History of Science and the Oikoumene", em HABIB e RAINA, 1999, pp. 16-28.

RESUMO - UM DOS principais objetivos da ciência é mostrar que "o mundo é inteligível pela razão humana”. Esta busca de compreensão racional tem uma história estreitamente ligada à história das ciências, mas também à das técnicas e à da filosofia, assim como à criação científica. Analisamos as relações entre construção social e historicidade, enfatizando a relevância dos conteúdos do conhecimento, os quais não se deixam dissolver nas condições externas de sua constituição. Toda a riqueza da historicidade pode ser vista na maneira orgânica pela qual estes conteúdos são tecidos a partir de materiais do mundo empírico assimilados em construções racionais. A própria historicidade torna-se-nos inteligível e permite entender as ampliações da racionalidade que possibilitam as aberturas, as invenções e os progressos do conhecimento.

Palavras-chave: História da Ciência; epistemologia; racionalidade.

ABSTRACT-ONE OF the main purposes of science is to show that "the world is intelligible" by human reason. This attempt at a rational comprehension has an history, which is closely linked to that of sciences, but also to that of techniques and of philosophy, and also with scientific creation. We examine the relationship between social construction and historicity, by putting emphasis on the importance of knowledge contents, that do not let themselves be dissolved in the external conditions of their constitution. All the richness of historicity shows itself in the organic way in which these contents are woven from materials of the empirical world assimilated in rational constructions. Historicity itself becomes intelligible to us, and allows us to conceive widenings of rationality that allow opening, invention and progress of knowledge.

Key-words: Science History; epistemology; rationality.

Michel Paty é professor visitante no Departamento de Filosofia da FFLCH-USP e Directeur de recherche émérite no Centre National de la Recherche Scientifique (Équipe REHSEIS, UMR 7596, CNRS et Université Paris 7-Denis Diderot). É autor de Einstein philosophe (Presses Universitaires de France, Paris, 1993); A matéria roubada (Edusp, São Paulo, 1995); A ciência nas relações Brasil-França (1850-1950) (ed. em colab., São Paulo, Edusp, 1996); La physique du XXe siècle, EDP-Sciences, Paris-Les Ulis, 2003; D’Alembert (São Paulo, Estação Liberdade, 2004). @ - paty@paris7.jussieu.fr

Texto traduzido do original em francês por René Lenard. O original em francês Intelligibilité rationnelle et historicié - encontra-se à disposição do leitor no IEA-USP para eventual consulta.

Recebido em 31/6/2005 e aprovado em 7/7/2005. 